\title{
A giant hematoma in the left atrial wall; A rare complication of percutaneous coronary intervention is $^{2}$
}

\author{
Mehmet Emre Özpelit a,*, Nihat Pekel ${ }^{a}$, Akar Yılmaz a , Caner Topaloğlu ${ }^{a}$, Erkan Şahin ${ }^{\text {b }}$ \\ a Izmir University, School of Medicine, Department of Cardiology, Izmir, Turkey \\ b Izmir University, School of Medicine, Department of Radiology, Izmir, Turkey
}

\section{A R T I C L E I N F O}

\section{Article history:}

Received 2 May 2016

Accepted 16 May 2016

Available online 21 May 2016

Keywords:

Intramural hematoma

Complication

Coronary intervention

\begin{abstract}
A B S T R A C T
Left atrial intramural hematoma ( $\mathrm{LAIH})$ is a rare complication of the percutaneous coronary interventions ( $\mathrm{PCI}$ ) which can cause severe hemodynamic instability. In this report a patient with a giant LAIH presenting with an acute cerebrovascular accident (CVA) is summarized.

(C) 2016 The Society of Cardiovascular Academy. Production and hosting by Elsevier B.V. All rights reserved. This is an open access article under the CC BY-NC-ND license (http://creativecommons.org/licenses/by-nc-nd/4.0/).
\end{abstract}

\section{Introduction}

LAIH is a very rare clinical entity that has been reported to occur either spontaneously or as a rare complication of cardiac intervention. We report a case of acute LAIH which had developed after PCI to the chronic total occlusion of right coronary artery (RCA). To the best of our knowledge, there is no analogous case of LAIH presenting with a CVA which has been reported previously.

\section{Case report}

A 66-year-old man who had undergone PCI for the left anterior decending (LAD) and circumflex artery (CX) three weeks ago was admitted for the management of his recurrent angina. His latest coronary angiogram showed the chronic total occlusion of RCA. He was managed medically; however, he continued to experience severe stable angina. On this hospital admission, he underwent a successful and challenging $\mathrm{PCI}$ for the chronic total occlusion of RCA. At the end of the procedure, there was a small rupture at the distal segment of the posterolateral artery presenting with a small amount of opaque extravasation to the pericardial cavity. (Fig. 1) The patient was totally asymptomatic with no sign of hemodynamic instability. Intraprocedural echocardiography showed no significant pericardial effusion.

\footnotetext{
is Authors declare no conflicts of interest.

* Corresponding author at: Izmir University, School of Medicine, Department of Cardiology, Yeni Girne Bvl., 1825 St. No: 12, Karsiyaka, Izmir, Turkey. Tel.: + 90232399 5050 (Internal: 2876); fax: + 902323995070.

E-mail address: emreozpelit@yahoo.com (M.E. Özpelit).

Peer review under responsibility of The Society of Cardiovascular Academy.
}

After the procedure, he experienced aphasia. Cranial CT was normal, however, diffusion magnetic resonance imaging (MRI) demonstrated a segment with a restricted diffusion in front of the central sulcus at the left lobe. Antiplatelet and anticoagulant treatment (unfractionated heparin, aspirin and clopidogrel) was applied to the patient immediately. There wasn't any sensorimotor deficit except for aphasia during the follow-up.

Echocardiogram was performed and showed a mass echogenicity arising from the lateral wall of the left atrium. The left atrium was almost totally filled with the mass causing a moderate restriction of the inflow through the mitral valve. (Fig. 2A,B) As the patient was hemodynamically stable, there was no need of an urgent operation, and patient was followed conservatively.

The patient underwent cardiac MRI to investigate the nature of the mass. MRI images showed, the mass as originating from the left atrial wall and protruding to the atrial cavity. The findings were concordant with a left atrial intramural hematoma. (Fig. 2C,D,E) Meanwhile carotis and vertebral artery Doppler ultrasound were totally normal.

$24 \mathrm{~h}$ later patient's aphasia was completely resolved. Serial followup echocardiography revealed a significant reduction in the size of LAIH. Patient was discharged from the hospital at the fourth day of hospitalization with a totally normal clinical situation. A control echocardiography was performed ten days later which showed complete resolution of the hematoma. (Fig. 3).

\section{Discussion}

Intralayer dissection of the LA wall following coronary artery perforation during coronary angioplasty is extremely rare. 

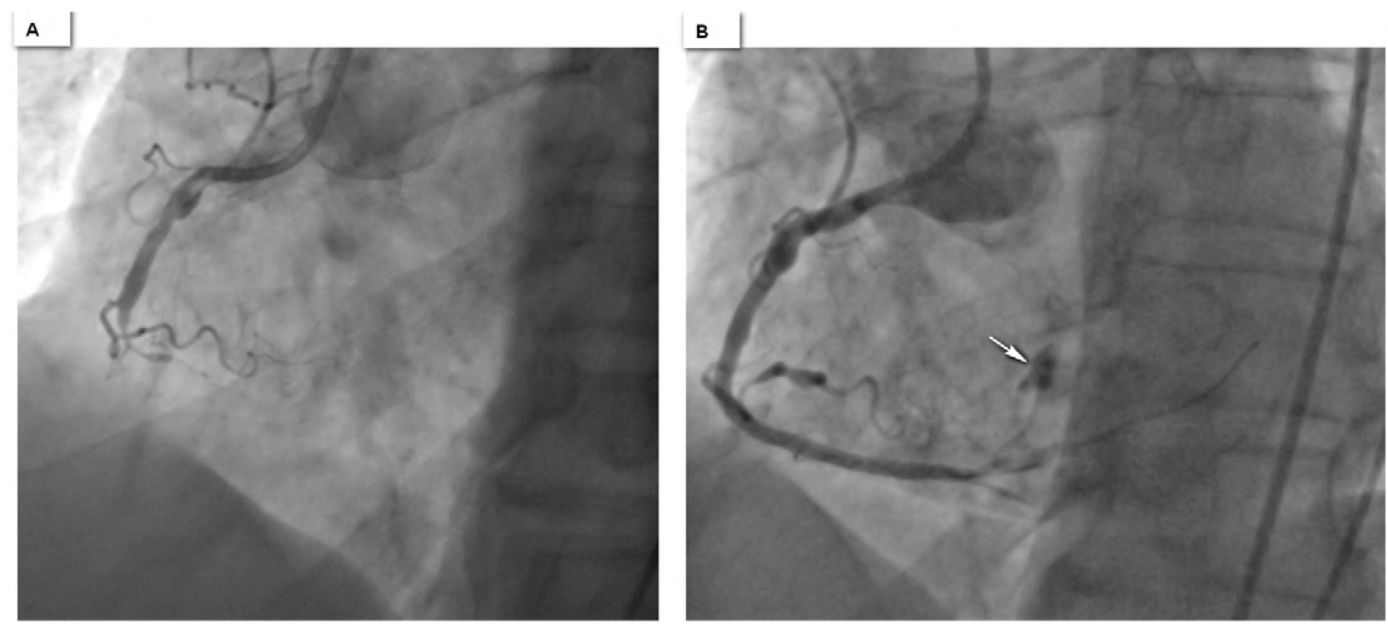

Fig. 1. Coronary angiography of the RCA before PCI (A), after PCI (B). Arrow indicating the extravasation of opaque.

Only a few similar, but not identical, cases have been described previously. We thought that the damage to the LA wall was caused during the positioning of the guide wire, which probably had penetrated the distal vasculature and caused the bleeding. Once there is an intramural bleeding, the low pressure within the left atrium allows the hematoma to enlarge into the atrial cavity. This is a potentially life-threatening complication necessitating clinical awareness, rapid diagnosis, and prompt treatment. Our case is the first case of LAIH presented with cerebrovascular symptoms. We speculate that cerebrovascular event is probably caused by concomitant partial endocardial layer dissection

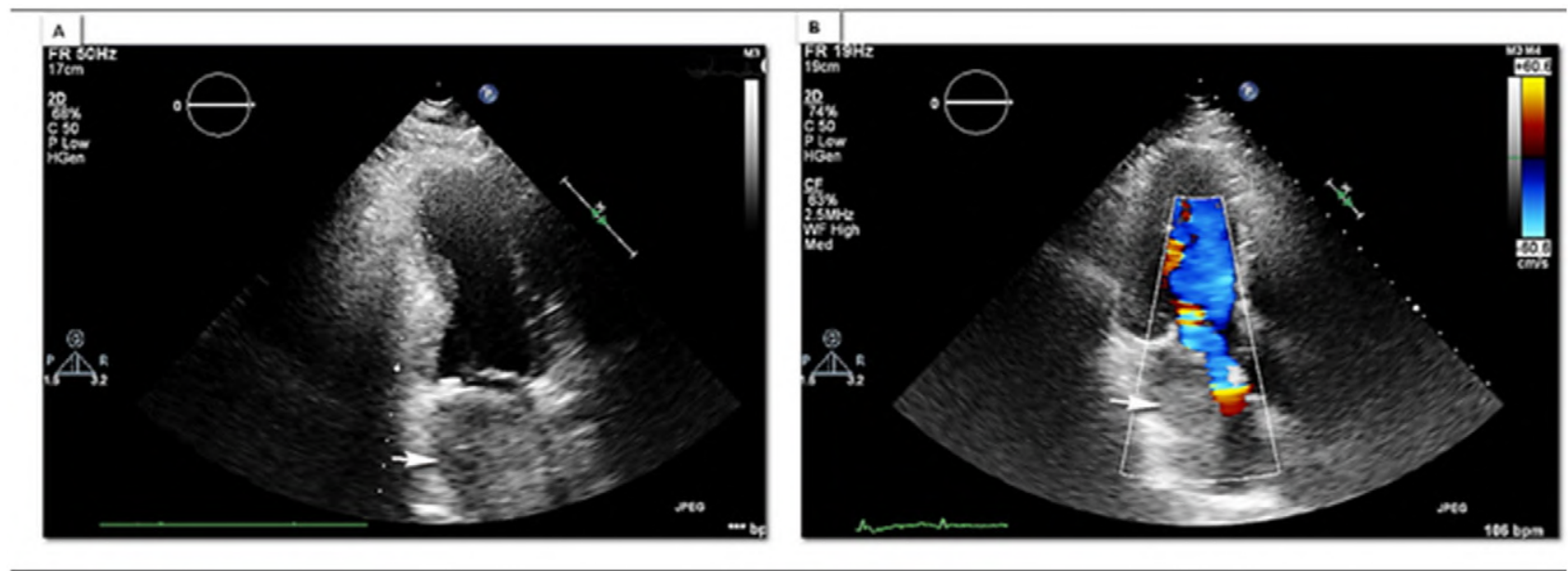

C

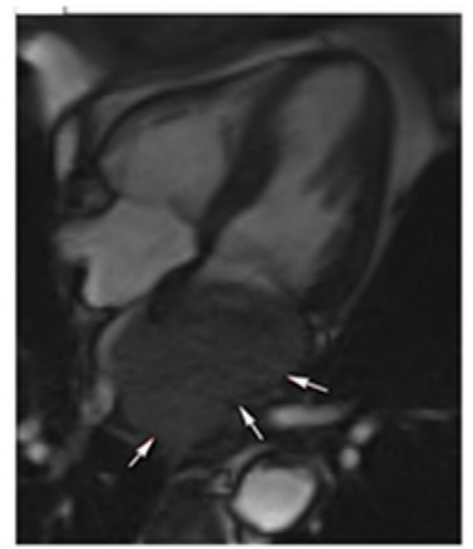

D

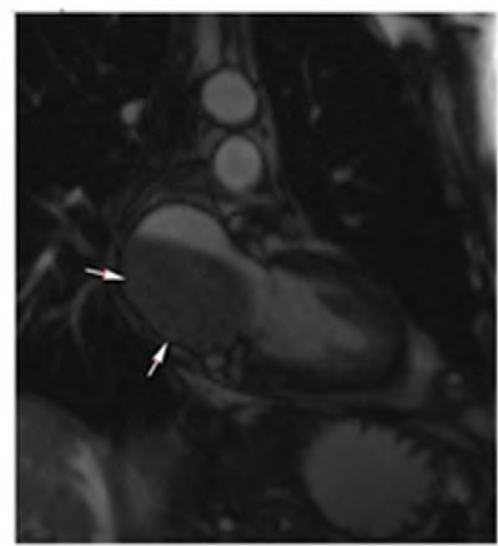

$\mathbf{E}$

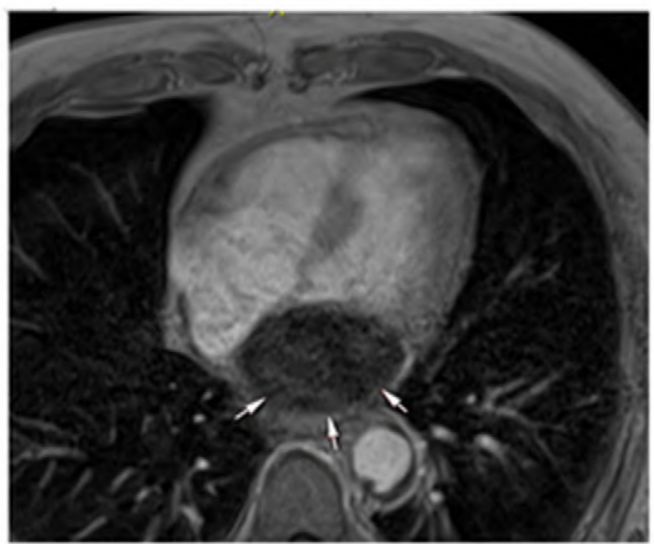

Fig. 2. Echocardiography showed a mass echogenicity arising from the lateral wall of the left atrium (A,B). MRI showed a giant left atrial intramural hematoma (C,D,E). 

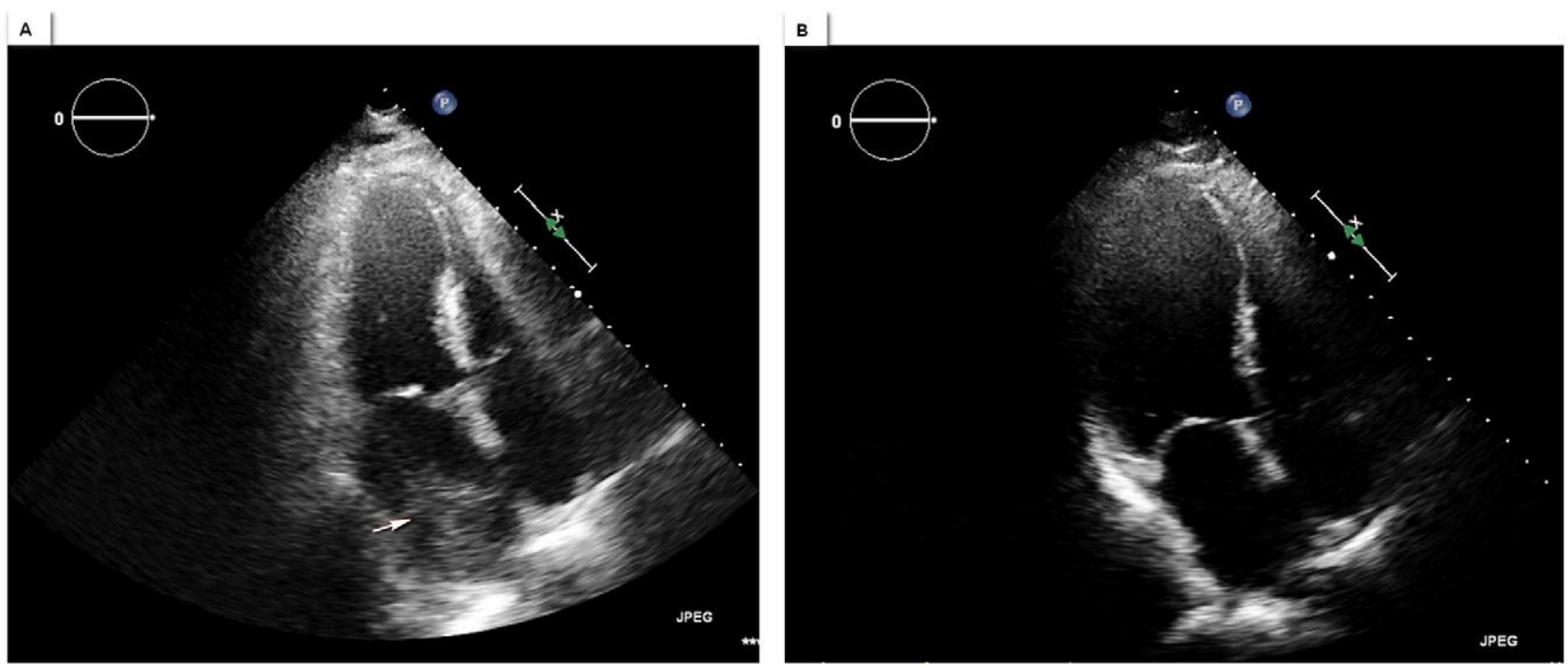

Fig. 3. Partial (A) and complete (B) resolution of hematoma.

letting the content of hematoma to pass to the systemic circulation. Endocardial layer dissection was demonstrated during the surgery of one previous case in the literature. ${ }^{1}$ There are a few cases of LAIH associated with coronary interventions and they were managed conservatively. ${ }^{2-4}$ Also some cases were treated surgically. ${ }^{1,5}$

\section{Conclusion}

LAIH is a rare complication of the PCI which can cause severe hemodynamic instability. Our case is the first in literature presenting with a CVA rather than a hemodynamic compromise. The literature data consist of individual case reports that no definite therapy can be described. Patients can be managed conservatively or surgically depending on the hemodynamic status. Awareness of this entity and its potential life threatening consequences is very important.

\section{References}

1. Cresce GD, Peluso D, Panfili M, Favaro A, Cannarella A, Picichè M, Salvador L. Left atrial wall hematoma as a consequence of percutaneous coronary angioplasty. Ann Thorac Surg 2012;93(3):e57-e59.

2. Solzbach U, Beuter M, Haas H. Left atrial intramural hematoma after percutaneous coronary intervention. Int J Cardiol 2010;141(2):e37-e38.

3. Galiuto L, Fedele E, Locorotondo G, Pisanello C, Favoccia C, Danza ML, Crea F. Intramural atrial hematoma: a rare complication of a common procedure. Echocardiography 2013;30(8):e255-e257.

4. Tavano D, Carlino M, Pisani M, Colombo A. Conservative treatment of a left atrial hematoma and a localized tamponade occurring during treatment of coronary total occlusion. Circulation 2007;115(22):e603-e606.

5. Jothidasan A, Attaran S, Hunter D, Souza AC. Management of a left atrial intramural hematoma after percutaneous intervention. Ann Thorac Surg 2014;97(6):e2196-e2197. 